\title{
The phonetics of Hebrew rhotics
}

Evan-Gary Cohen ${ }^{\mathrm{a} *}$, Lior Laks ${ }^{\mathrm{b}}$, Carmen $\mathrm{Savu}^{\mathrm{c}}$,

*Corresponding author: evan@post.tau.ac.il, Tel: +972 77 8844013, Fax: +972 36405109

a Tel-Aviv University, POB 39040, Tel-Aviv, Israel

b Bar-Ilan University, Ramat-Gan 5290002, Israel (lior.laks@biu.ac.il)

${ }^{c}$ UiT - The Arctic University of Norway, Breiviklia N211, 9019 Troms $\varnothing$, Norway

(carmen.savu@uit.no)

\begin{abstract}
This paper investigates manner variation of Israeli Hebrew rhotics with respect to two factors: prosodic position and speaker gender. An acoustic experimental study shows that although the Hebrew rhotic phoneme tends to be a dorsal approximant, it is significantly more likely to undergo fortition in onset position. This fortition is a result of target overshoot, the rhotic subsequently being produced with a greater degree of constriction than that which would have resulted in an approximant, subsequently surfacing as a stop, a fricative, a tap or a trill. Furthermore, in onset position, female speakers show more variation and produce fewer approximants than male speakers.
\end{abstract}

\section{Keywords}

rhotic; Hebrew; allophony; onset fortition 


\section{Onset fortition in Hebrew rhotics: The effects of prosody and gender}

\subsection{Introduction}

This paper addresses the apparent controversy regarding the phonetic nature of the Israeli Hebrew (henceforth: "Hebrew") rhotic. ${ }^{1}$ We discuss various effects on the manner of articulation of the Hebrew rhotic, controlling for prosodic position and gender, and their subsequent phonological implications.

This research differs from previous researches in that it is the first of its kind ever conducted in Hebrew with respect to the number of speakers, the methodology, the amount of acoustically analysed data, the controls, and the degree of the allophonic variation observed. Many previous studies (e.g. Segal 1928, Torczyner 1936, Gottstein 1948, Siegelman 1950, Storm 1974, Schwarzwald 1981) did not focus on native speakers of Hebrew. ${ }^{2}$ Most (e.g. Blanc 1964, Bolozky 1978, 1997) did not conduct acoustic analyses their studies. Furthermore, some of these studies dealt with both the dorsal rhotic and the alveolar rhotic. Nowadays, however, alveolar productions are found almost exclusively with native speakers of other languages (see Laufer 1992, detailed in \$4.1) or certain pronunciations in media broadcasts and singing. ${ }^{3}$ This study will, therefore, only focus on the dorsal rhotic.

Note, there are some acoustically-based studies (e.g. Laufer 1986, Bolozky\&Kreitman 2007, Bolozky 2009) which do focus on Hebrew dorsal rhotics, and even have acoustic analyses. Laufer's (1986) acoustic study examines the rhotic of one Israeli-born Hebrew speaker whose parents were not from Arabic-speaking countries, and defines the rhotic as a frictionless dorsal (velar/uvular, or between the velum and uvula) continuant (pg. 76, 82, 93), and states

\footnotetext{
${ }^{1}$ Israeli Hebrew or Modern Hebrew, as spoken in present-day Israel by native speakers of Hebrew, whose parents are also native speakers of Hebrew.

${ }^{2}$ See 4.1 .

${ }^{3}$ Historically, the Hebrew rhotic, similarly to other Semitic languages, was probably an alveolar trill or tap, but this is not evident in the vast majority of speakers (and almost all the native speakers) of Israeli Hebrew, where only a dorsal rhotic is used.
} 
that some researchers refer to the rhotic as a fricative, but all cited therein refer to it as dorsal, though additional speakers need to be investigated.

The current study also controls for gender (unlike any previous study of Hebrew), as this has been shown to be relevant in many phonetic issues such as vowel quality (Most et al. 2000) and space (Pierrehumbert et al. 2004). ${ }^{4}$

Cross-linguistically, from the phonetic point of view, rhotics form a heterogeneous group. They exhibit a variety of manners and places of articulation (uvular fricatives in French, alveolar trills in Arabic, alveolar taps in Japanese, approximants and r-coloured vowels in English, combinations of features of several of these categories - Ladefoged \& Maddieson 1996: 217). Phonologically, rhotics typically undergo a variety of processes such as pseudoreduplication in Hebrew loanwords (Cohen 2013), ${ }^{5}$ deletion or vocalisation (Lindau 1985, Itô \& Mester 2001), metathesis (Bolognesi 1998, Hoole et al. 2013, Savu 2012, Cohen 2013) and more. The current study investigates the manner of articulation of the Hebrew rhotic, and the relation between manner, prosodic position and gender.

We show that the nature of the Hebrew rhotic is more context-dependent than previously claimed. Word-initial rhotics are less likely to be approximants compared to word-medial (intervocalic) and word-final rhotics. In addition, female speakers are more likely than male speakers to produce non-approximant rhotics.

Note, the symbol /s/ will be used throughout this paper for the Hebrew rhotic category.

\subsection{Experimental materials and methods}

An experiment was conducted in order to examine the connection among manner, prosodic position and gender. The participants produced rhotics in words within frame sentences in various prosodic environments.

\footnotetext{
${ }^{4}$ Though we controlled for gender, we admittedly had no expectations.

${ }^{5}$ Pseudo-reduplication refers to cases in which rhotics are metathesized out of coda position and into an onset position resulting in a form which appears to be reduplicated.
} 


\subsection{Participants}

24 adult native speakers of Hebrew (12 male, 12 female) with no known language impairments participated in the experiment. Aged 20-40 (average age: 26.75), all participants' parents were native speakers of Hebrew, and none were aware of the objective of the experiment.

\subsection{Materials}

Three word-types based on prosodic structure were used, two words for each type, a total of 6 different words. The word-types were: words with initial /\#ва/ sequences, words with medial /ава/ sequences, words with final /аь\#/ sequences (see table 2 in Appendix A). The words were placed within frame sentences (6 sentences per speaker). Words with initial rhotics were sentence-initial (post-pause), words with final rhotics were sentence-final (pre-pause). No effects for word frequency or morphological category (noun vs. verb) were found (see examples in table 3 in Appendix B).

\subsection{Procedure}

The frame sentences were presented in Hebrew orthography on a computer screen to each participant in pseudo-random order. They were instructed to read the sentence to themselves, and then pronounce the sentence three consecutive times, breaking in between pronunciations. After completing the three pronunciations, the participants clicked on the screen to proceed to the next sentence. Some list-intonation in the pronunciations of each triplet was observed, but this was not found to affect the variable pronunciations of the rhotic, i.e. no pattern was found which correlated with the placing of the sentence within each triplet. Each sentence was produced three times by each speaker, a total of 18 sentences per speaker. Although the frame sentences were not identical for all speakers, the phonological environments of the rhotics were identical. All three productions were analysed. 


\subsection{Analysis}

All data were analysed by the authors using PRAAT (Boersma\&Weenink 2013). The rhotics (waveforms and spectrograms) were investigated with respect to acoustic correlates of various manners of articulation (based on Catford 1977, Ladefoged\&Maddieson 1996, Johnson 2012). The following table 1 is an exhaustive list of the manner categories we refer to. Note, the manners of articulation presented in the following table 1 are arranged according to the degree of the closure, in ascending order, from approximants (frictionless open approximation) to plosives (complete closure).

Table 1 Summaries of manners of articulation

\begin{tabular}{ll}
\hline \multicolumn{1}{c}{ Manner } & \multicolumn{1}{c}{ General description } \\
\hline Approximant & Vowel-like, no frication over more than $50 \%$ of the stricture \\
Dirty vowel & Vowel-like, superimposed frication over more than $50 \%$ of the stricture \\
Fricative & Not vowel-like, frication over more than $50 \%$ of the stricture \\
Tap & Vocalic material interrupted by very short constriction, no burst \\
Trill & Similar to tap with at least two interruptions \\
Plosive & Longer constriction, interruption in the vowel-like material, burst/release
\end{tabular}

The distinction among the manners of articulation is scalar, reflecting the degree of closure and its duration. The division among categories may be somewhat arbitrary (Catford 1997:125 on the division between approximants and fricatives), and we have referred to specific acoustic cues in order to overcome this. Such is the division among approximants, dirty vowels and fricatives, where we refer to the percentages of the closure with noticeable frication and amplitude, both of which are scalar, the cutoff points being arbitrary. Approximants, the most open degree of constriction, are distinguished from all other manners of articulation by the continuous flow of air, the lack of frication, the vowel-like waveform 
and spectrogram, and the relatively high amplitude (compared to other manners of articulation). Rhotics are only categorised as approximants when most of the closure (usually very close to $100 \%$ ) has no visible frication. Dirty vowels and fricatives are distinguished from approximants by the presence and extent of frication and the dramatic drop in amplitude compared to approximants. ${ }^{6}$ Because of the articulatory precision required in the articulation of fricatives, minute differences in the channel created by the articulators create a great deal of difference in the actual production and the degree of frication (Ladefoged\&Maddieson 1996:137). When frication, due to closer approximation of the articulators, is visible over most of the constriction, the rhotics are either categorised as dirty vowels (frication superimposed on vocalic waveforms) or as fricatives (no noticeable vocalic waveforms over most of the constriction). Dirty vowels are arguably fricatives with a lesser degree of frication than the latter. We propose this category, distinguishing between it and the fricatives by how vocalic the waveform appears (vocalic=dirty vowel, non-vocalic=fricative).

The remaining three manners of articulation involve a greater degree of closure than the first three. They differ from one another by the duration of the closure, the elements adjacent to the constriction and the number of constrictions. Acoustically, plosives differ from the other two manners in two primary aspects, the duration of the closure leading up to the release and the plosion itself. While taps and trills may have brief pauses in their structure, the closure itself is much shorter than in plosives, and the release is directly into vocalic material with very little or no noticeable plosion. Note, taps in word-initial and word-final position have a vowel on one side and a pause on the other. In these contexts, however, studies show that brief vocalic elements flank the constriction on the side where the pause should be. This happens cross-linguistically (Avram 1993 and Savu 2012 for Romanian, Vago and Gosy 2007 for

\footnotetext{
${ }^{6}$ Although the source of the frication cannot always be determined based solely on an acoustic analysis, dirty vowels and fricatives can also be distinguished from approximants on the basis of the huge differences in amplitude.
} 
Hungarian, Baltazani and Nicolaidis 2011a, b for Modern Greek, and more). ${ }^{7}$ We differentiate between trills and taps solely on the basis of the number of visible constrictions - one for taps, more than one for trills.

\subsection{Results and analysis}

All six manners of articulation in table 1 were found in the data. The following figures 1-6 show one example for each manner of articulation, each followed by a brief discussion. Since the rhotics are all vowel-adjacent $(/ \mathrm{a} /)$ in this study, the boundaries were determined by the onset and offset of vowel formants (particularly F1 and F2) typical of Hebrew /a/, the drop in amplitude when transitioning from the vowel into the adjacent rhotics, voicing (when relevant) and the lack of frication (when relevant). The following words in the full context of the frame sentences appear in Appendix C.

Figure 1 Plosive - [q]atsiti 'I wanted'

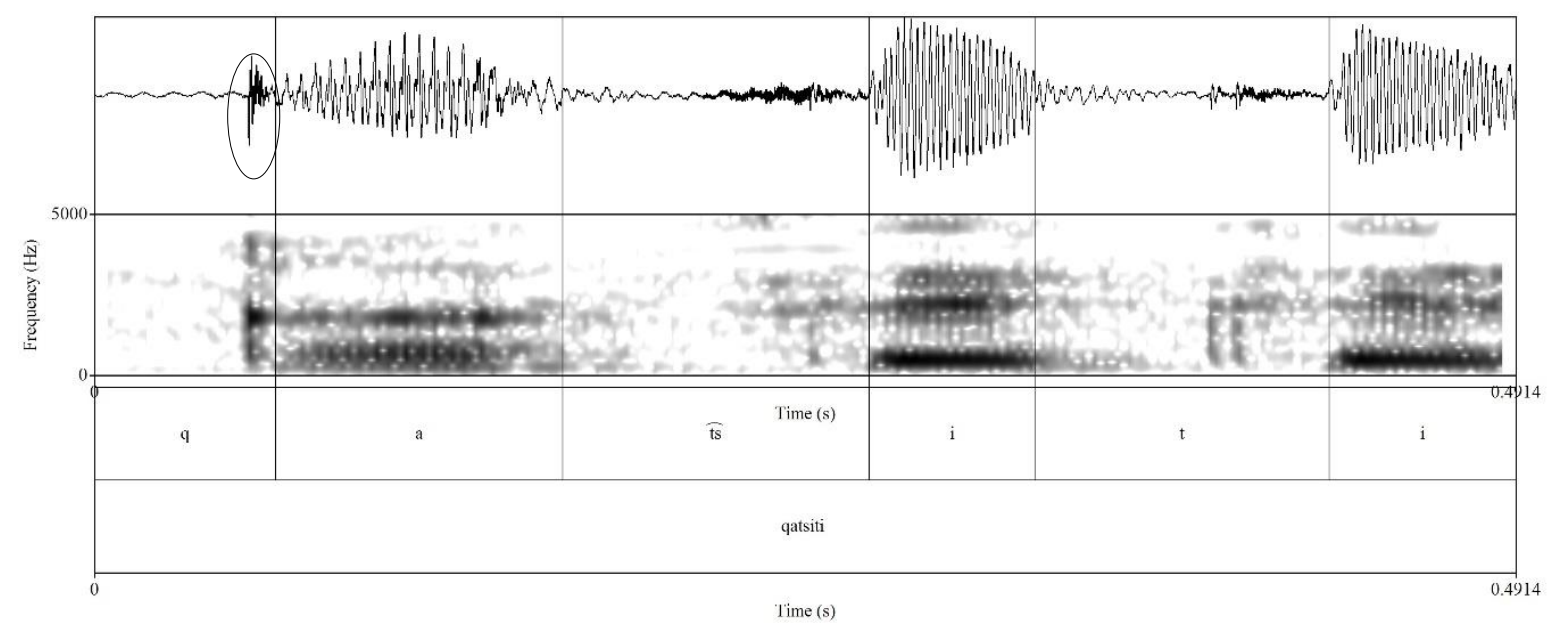

The plosion (circled in waveform) precedes the vowel /a/. Note, the word is utterance-initial, post-pause, therefore nothing precedes the /ь/ itself.

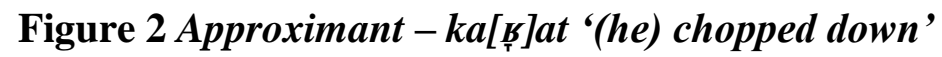

\footnotetext{
${ }^{7}$ Trills differ from taps articulatorily with respect to muscle tension and tongue configuration. However, it is important to note that when only observing the acoustics of the rhotics, these differences cannot be determined.
} 


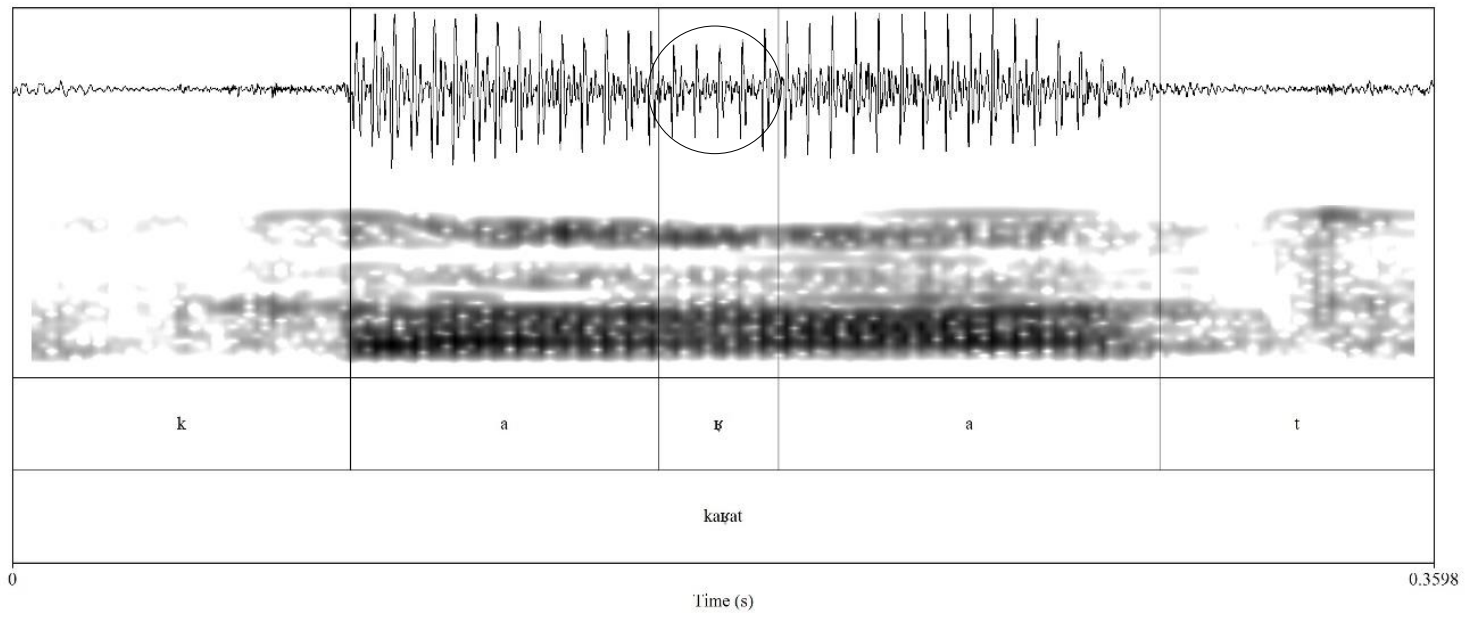

The rhotic is circled (in waveform). The amplitude of the waveform is noticeably smaller than the flanking /a/ vowels. There is no frication throughout the duration of the rhotic.

Figure 3 Dirty vowel-ka[a]at '(he) chopped down'

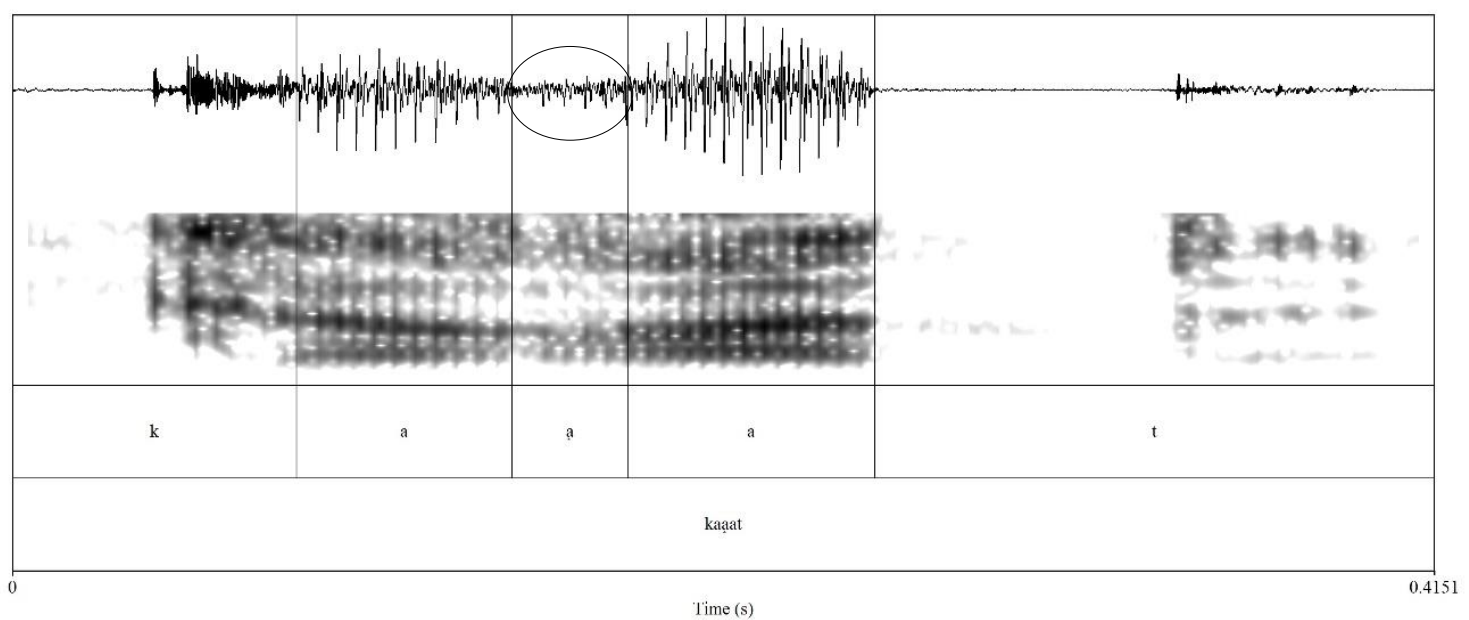

The amplitude of the waveform (circled) is noticeably smaller than the flanking /a/ vowels.

There is frication superimposed on the rhotic but not on the adjacent vowels. There is a striking difference between figures 2 and 3 . 


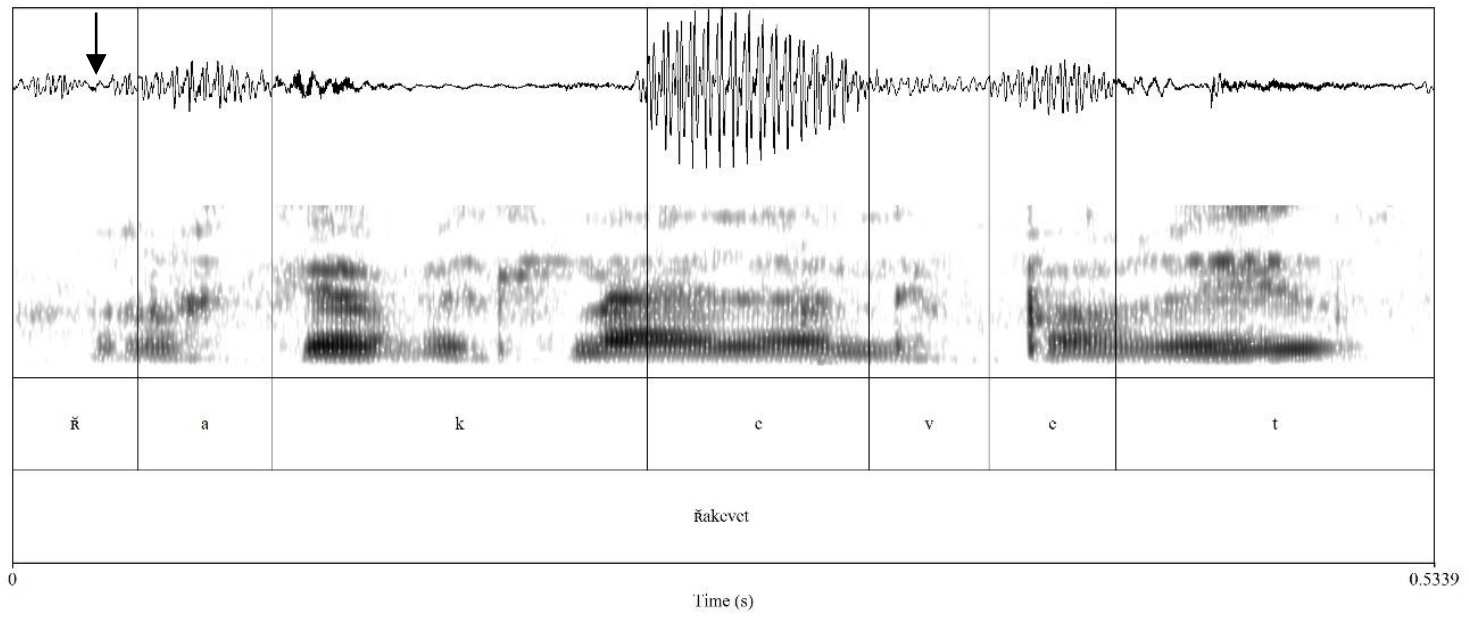

This is an utterance-initial tap, therefore, there is some vocalic material before the closure, followed by the vocalic material of the adjacent /a/ vowel (end of initial vocalic material + closure + beginning of final vocalic material. The closure is marked by the arrow in the waveform. See also discussion of utterance-initial taps in §2.4).

\section{Figure 5 Trill-ka[R]at '(he) chopped down'}

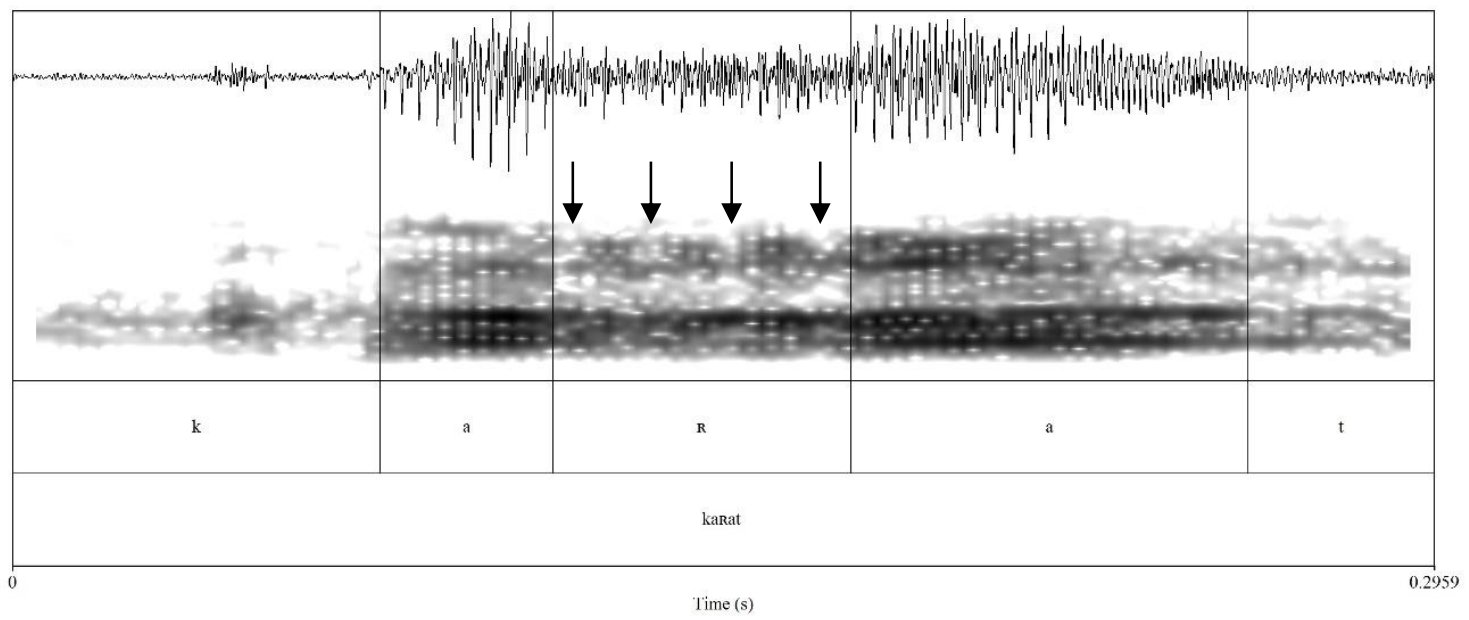

The trill consists of four short breaks in the vocalic material (marked in spectrogram). 
Figure 6 Fricative - [b]afamti '(I) wrote’

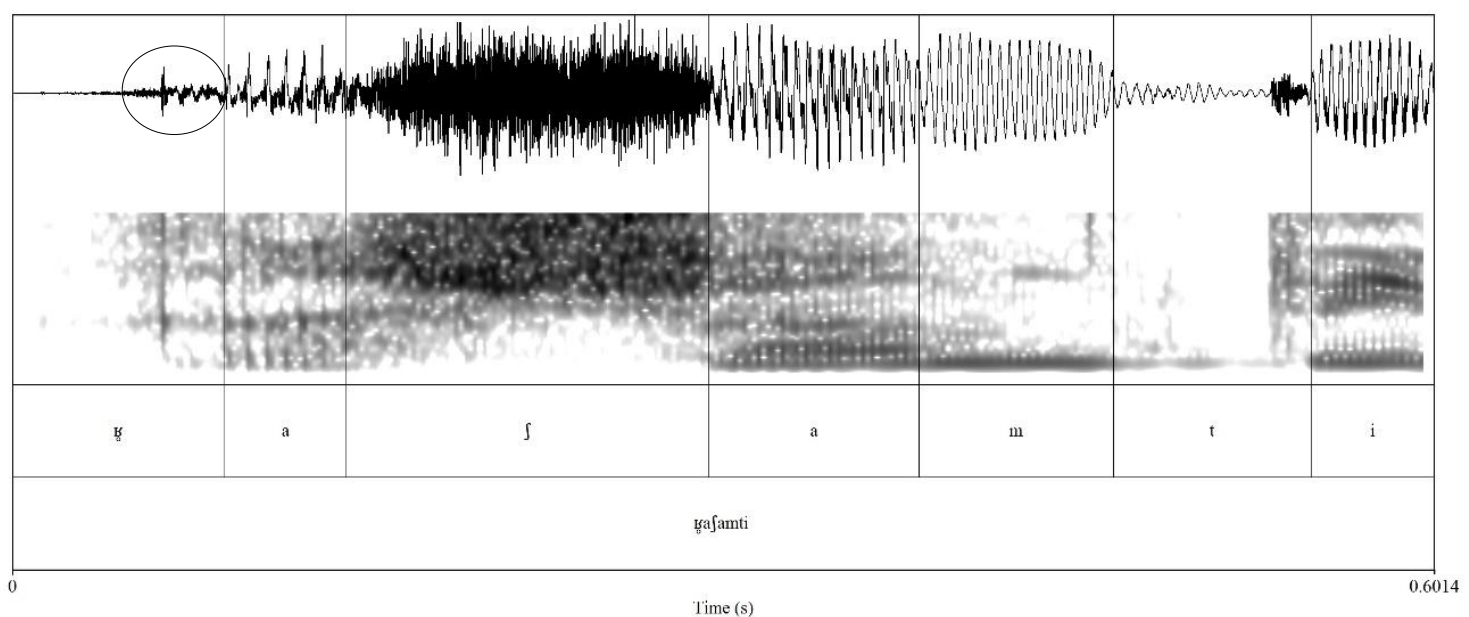

The rhotic (circled in waveform) has considerable frication and is, in this case, voiceless.

Note, the waveform is noticeably different from the above approximant (figure 2) and dirty vowel (figure 3) rhotics.

The various forms, however, are not distributed evenly over the various manners of articulation. The following figure 7 shows the number of tokens for each manner of articulation.

Figure 7 Manner of articulation - Overall (absolute numbers)

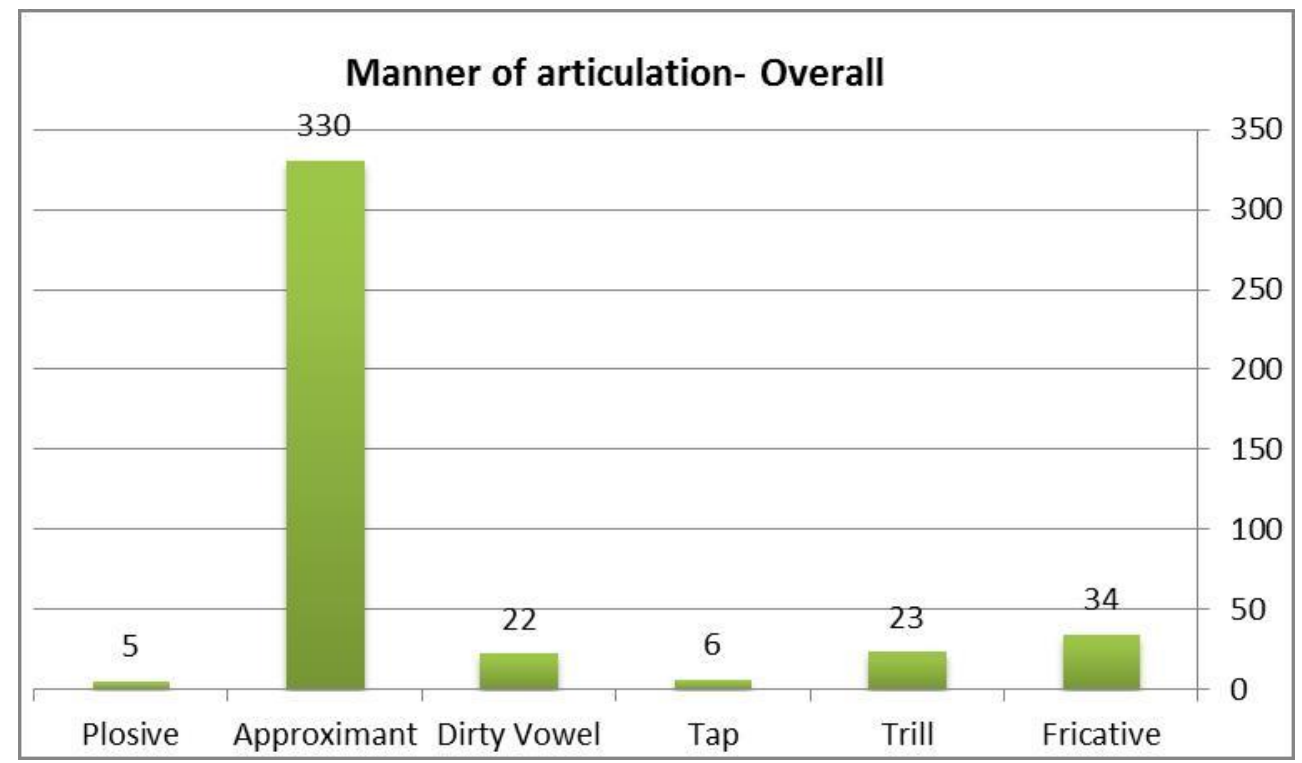

Approximately $79 \%$ of the 420 tokens analysed were approximants (12 tokens out of the 432 produced were not analysable). Generally speaking, rhotics are statistically approximants $\left(\chi^{2}\right.$ $=31.66, \mathrm{P}<0.0001)$. However, when controlled for prosodic position and gender, this 
generalisation does not necessarily hold, as shown in $\S 3.1$ (prosodic position) and $\S 3.2$ (prosodic position+gender).

\subsection{Manner of articulation by prosodic position}

Although rhotics tend to be approximants, there is a significant effect of prosody on the likelihood of a rhotic being an approximant as opposed to a non-approximant.

The following figure 8 presents the distribution of the manners of articulation over the various prosodic positions.

Figure 8 Approximants vs. Non-approximants - by prosodic position (absolute numbers)

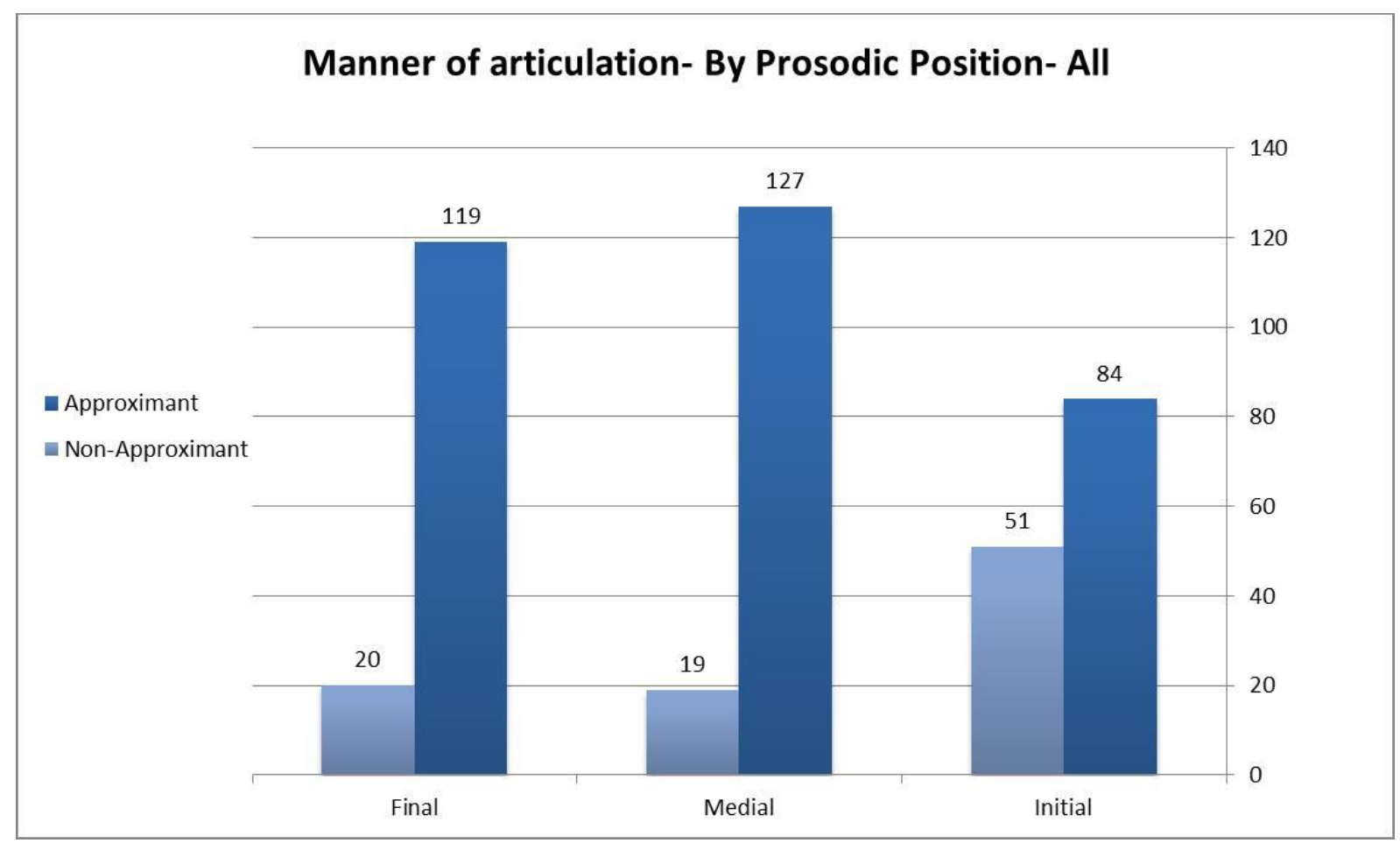

There is a significant correlation between the variables manner (approximant vs. nonapproximant) and position (initial vs. non-initial). Initial rhotics are almost three times more likely to be non-approximants than non-initial rhotics $\left(\chi^{2}=30.17, \mathrm{P}<0.0001\right)$, i.e. initial rhotics vary more than rhotics in other positions. There is no significant statistical difference between medial rhotics and final rhotics with respect to their likelihood of being approximants. 


\subsection{Manner of articulation by position+gender}

The likelihood of a rhotic being a non-approximant for females is considerably higher than for males (non-approximants: $25 \%$ of female rhotics vs. $18 \%$ of male rhotics). However, this difference is not statistically significant $(\mathrm{P}=0.1138)$.

Significant differences between male and female speakers do show up when checking the manners of articulation by gender and position, as shown in figure 9 .

Figure 9 Approximants vs. Non-approximants - by prosodic position and gender (absolute numbers)

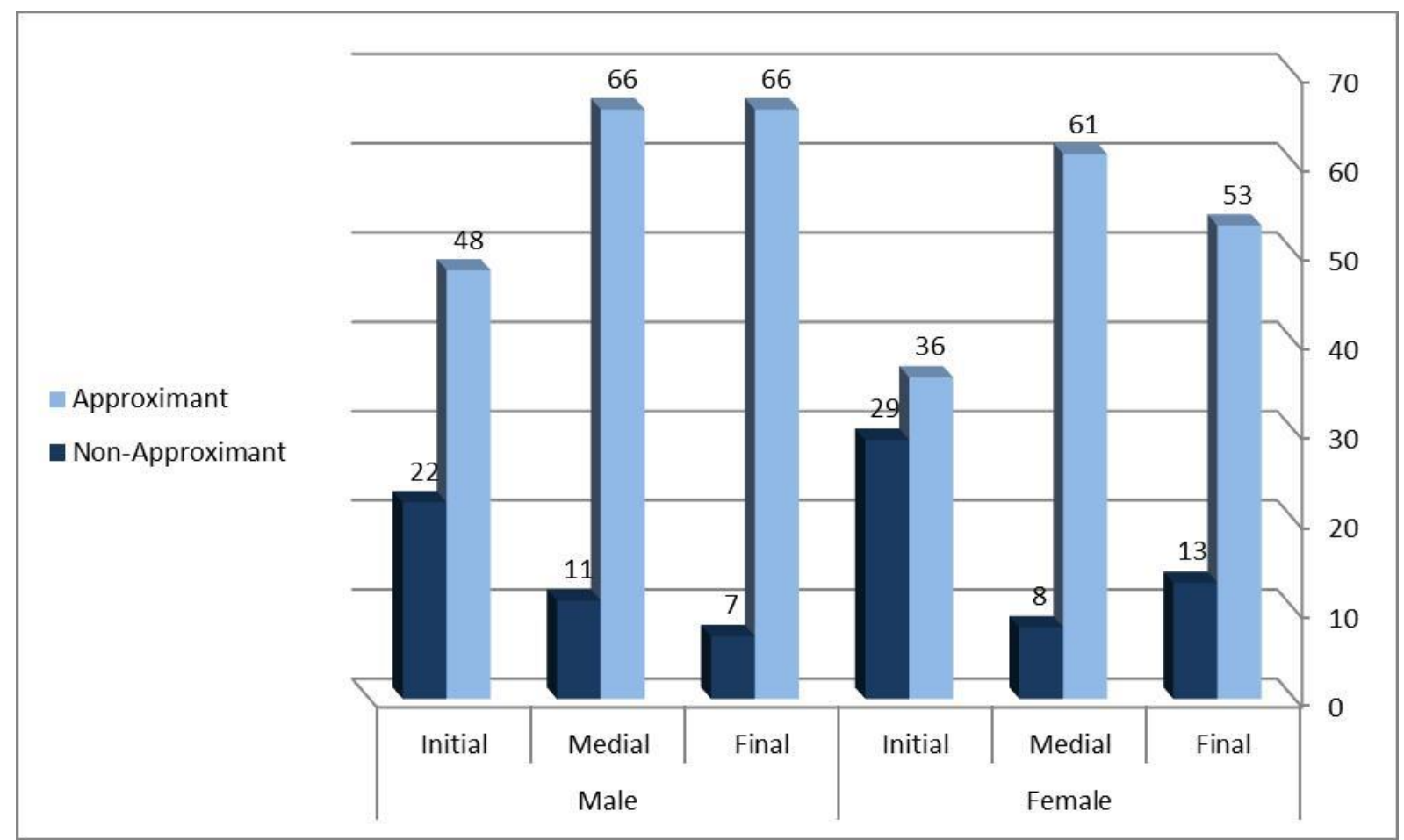

It is statistically significant that female rhotics are approximants regardless of position $\left(\chi^{2}=\right.$ 20.94, $\mathrm{P}<0.0001)$, as are male rhotics $\left(\chi^{2}=12.67, \mathrm{P}=0.0018\right)$. The initial positions vary the most - for females $44 \%$ of initial rhotics are non-approximants, a significant relationship $\left(\chi^{2}=\right.$ 18.24, $\mathrm{P}<0.0001$ ), while for males $31 \%$ of initial rhotics are non-approximants, also significant $\left(\chi^{2}=10.84, \mathrm{P}=0.001\right)$. The relationship between the variables medial (medial vs. non-medial) and manner (approximant vs. non-approximant) is significant in general $\left(\chi^{2}=\right.$ 
$8.66, \mathrm{P}=0.0033)$ and for females $\left(\chi^{2}=9.03, \mathrm{P}=0.0027\right)$, but not significant for males $(\mathrm{P}=$ $0.3594)$.

\subsection{Discussion and conclusions}

The Hebrew rhotic is significantly more likely to be a non-approximant in onset position, more so for women than men. Assuming an approximant target, this behaviour demonstrates the higher likelihood of target overshoot in the fortified word-initial onset position as opposed to the higher likelihood of target undershoot in coda position. Similar processes have been documented in other languages for rhotics (.e.g. German uvular rhotics - Raffelsiefen 2014: target is uvular trill, target overshoot in onset produces uvular fricatives, target undershoot in coda produces vowel), and for other segments, such as /s/-lengthening in onset position (Cho et al. 2014), glide fortition in Spanish (Harris \& Kaisse 1999, Baker \& Wiltshire 2003), as well as general domain-initial articulatory strengthening (Smith 2002, Cho \& Keating 2009). This allophonic variation of rhotics not only resolves outstanding issues regarding the phonetic nature of Hebrew rhotics, but also sheds light on possible explanations for previously little understood processes involving these sounds in Hebrew.

\subsection{Shedding light on previous studies}

Previous studies of Hebrew rhotics present seemingly contradictory descriptions of the surface forms. Note, none of them discuss context-dependent variation or allophony. Some early studies of Hebrew rhotics (see also §1) describe them as alveolar trills or taps (Segal 1928:30, 33, 36), gutturals (Torczyner 1936:42), alveolar-dental or uvular trills (Gottstein 1948), or varying among alveolars, dentals, gutturals or dorsals (Siegelman 1950:8), sometimes depending on the origins of the speakers (Ashkenazi vs. Sephardi Jews). ${ }^{8}$ The language backgrounds of speakers played a significant role too. For example, Arabic-

\footnotetext{
${ }^{8}$ Note, if one discusses the origins of the speakers, then we can only assume that these are not necessarily native speakers of MH.
} 
background speakers produce alveolar trills in Hebrew, while French-background speakers produced dorsals. Nowadays, primarily monolingual speakers whose parents are native speakers of Hebrew produce, almost exclusively, dorsal rhotics.

These studies are followed by others, such as Blanc (1964), who describes Hebrew rhotics as velar fricatives, Bolozky $(1978,1997)$, Storm $(1974: 15,17)$ as uvular fricatives, Schwarzwald (1981) as alveolar trills, uvular fricatives/trills/plosives/taps, ${ }^{9}$ Laufer (1986) as dorsal frictionless continuants, ${ }^{10}$ Laufer (1992) as alveolar trills and uvular trills/fricatives/approximants, ${ }^{11}$ Bolozky \& Kreitman (2007) as uvular approximants with frication, ${ }^{12}$ Bolozky (2009) as approximant sonorants. All these manners of articulation are indeed attested in the current study. ${ }^{13}$ So, in fact, the multiple surface forms were all identified in various studies, though they generally did not deal with allophony. Our study adds to previous ones by describing and accounting for the apparent allophony. In fact, the current study generally reconciles the above analyses, at least with respect to the actual manners of articulation observed. The major contribution is that it addresses the variation, showing that the nature of the Hebrew rhotic is a lot more context dependent that previously thought.

The two major generalisations are: (i) word-initial rhotics are less likely to be approximants compared to word-medial (intervocalic) and word-final rhotics. (ii) Female speakers, in all contexts, are less likely than male speakers to produce approximant rhotics.

\subsection{Phonological implications}

\footnotetext{
${ }^{9}$ The alveolar productions Schwarzwald refers to were by 15 speakers of the 89 in her study. 14 of these were from Arabic speaking countries, and the remaining speaker was from Southern France.

${ }^{10}$ Based on one Hebrew speaker born in Israel to parents who were not from Arabic-speaking countries.

${ }^{11}$ Laufer $(1992: 29,35,37)$ describes the alveolar trill as being typical of mainly speakers with an Italian, Romanian, South American or Arabic background. The current study only investigated native speakers of Hebrew whose parents were both native speakers of Hebrew. Though describing the dorsal rhotic as an approximant (pg. 37), Laufer uses the uvular fricative IPA symbol (pg. 28) and describes it as being similar to the French rhotic (29), which is generally considered to be a trill (pg. 47) or fricative.

${ }^{12}$ Based on two speakers, no details of the speakers were provided.

${ }^{13}$ All productions attested in the current study were dorsal. No alveolar rhotics were recorded.
} 
The phonetic behaviour of the Hebrew rhotic will lead us to a better understanding of its phonology, as the following examples in $\S 4.2 .1$ and $\$ 4.2 .2$ show.

\subsubsection{Metathesis}

Hebrew rhotics also display unusual behaviour in loanwords (Cohen 2013) undergoing metathesis out of coda position (е.g. /ревspektiva/ $\leftarrow$ [рвеspektiva] 'perspective', /endosfinim/ $\leftarrow$ [endsofinim] 'endorphins'). Other consonants in loanwords do not undergo metathesis. Given that rhotics are generally approximants, the mechanism of this metathesis could be captured in terms of the analysis described in Savu (2012) for tap metathesis, i.e. a movement of the constriction along a vocalic continuum. Approximants (and perhaps dirty vowels) might be easier to move on a vocalic continuum, since they are vocalic material. This line of reasoning covers onset rhotics that remain approximants. If the coda rhotic, which is metathesized into onset position, becomes a tap, trill, fricative or plosive, this might be done in order to dissimilate it from surrounding vocalic material. Presumably, this would be more difficult to accomplish in a coda position, as codas frequently exhibit undershoot for any type of consonant. Therefore, we would be dealing with metathesis in order to bring the rhotic into a position where it has a better chance of being fortified, and the change in manner of articulation would be a kind of dissimilation (making the rhotic less vocalic) for the purposes of greater perceptual salience. However, if the need for perceptual salience indeed drives this phenomenon, we would expect more fortition in medial position, where approximant rhotics are flanked on both sides by full vowels. Perhaps, in the case of medial rhotics, the need for articulatory ease overpowers the need for perceptual salience, and rhotics remain approximants.

\subsubsection{Acquisition}

The acquisition of the Hebrew rhotic presents us with a number of phenomena which have thus far eluded explanation. The rate of the rhotic's acquisition is notoriously slow (Ben- 
David 2001: 56), more so than most other consonants, and it is the last consonant to be acquired by second language learners. In addition, rhotics are strangely fully acquired in coda position before onset position, contrary to most other consonants in Hebrew (with the exception of stridents). Finally, Ben-David et al. (submitted) report that rhotics are substituted by a variety of segments ([1], [j], [x], [y] inter alia), depending on their prosodic position. These phenomena could be due to the allophonic complexity of rhotics in onset position as opposed to the relative consistency in coda position.

\subsection{Ongoing and future research}

This study of the allophony of Hebrew rhotics focuses on /a/-adjacent rhotics in various prosodic positions. An obvious direction for future study would be the investigation of other environments (e.g. different vowels, consonant-adjacent rhotics, rhotics in complex onsets and complex codas). Furthermore, future studies should include additional phonetic methodologies, such as ultrasound analyses to determine the precise places of articulation. While this study focuses on native speakers of Hebrew whose parents are native Hebrewspeakers, Heritage Hebrew and second language Hebrew are interesting directions for future investigation, where variation is expected to be substantial, as many of the above mentioned studies show.

The implications of this study for various phonological questions are broad. Allophonic variation of rhotics and its effect on acquisition, for example, have been studied (Cohen 2015), and the clinical implications of these affects are currently being investigated (Cohen\&Ben-David 2016).

No doubt, a better understanding of the phonetics of the Hebrew rhotic would facilitate a better understanding of its complex phonology. 


\section{Acknowledgements}

A special thanks to Stav Klein for her contribution. We would also like to thank the participants of fourth international conference on rhotics, r-Atics 4, Bernin (29-31.10.2013) for their invaluable input. The usual disclaimers hold.

\section{Appendix A}

Table 2 Examples of tokens used in experiment

\begin{tabular}{|c|c|c|}
\hline Word & Gloss & Position \\
\hline ваav & hunger & initial \\
\hline ваiti & I saw & initial \\
\hline ваkevet & train & initial \\
\hline ва Jamti & I wrote & initial \\
\hline кат̈siti & I wanted & initial \\
\hline ьакаd & hail & medial \\
\hline јаваd & he descended & medial \\
\hline kаваs & it collapsed & medial \\
\hline kаьаt & he amputated & medial \\
\hline рава & he retired & medial \\
\hline atsá & he stopped & final \\
\hline jakав & expensive & final \\
\hline јалав & straight & final \\
\hline katsac & short & final \\
\hline maxав & tomorrow & final \\
\hline
\end{tabular}




\section{Appendix B}

Table 3 Examples of frames used in experiment

\begin{tabular}{|c|c|c|}
\hline Frame & Gloss & Position \\
\hline каtsiti livdok mi ze & I wanted to check who it was & Initial \\
\hline ваkevet tsafon tеахев hajom & The northern train will be late today & Initial \\
\hline ehud bаваk ракал mehaxajim hapolitiim & Ehud Barak retired from political life & Medial \\
\hline hitxil lasedet bакаd al hagag & Hail began to fall on the roof & Medial \\
\hline ani nosea latsafon махақ & I'm travelling to the North tomorrow & Final \\
\hline dani hu adam jалав & Danny is an honest person & Final \\
\hline
\end{tabular}

\section{Appendix C:}

The following are the complete contexts within the frame sentences of the words which appear in $\$ 3.0$.

Plosive - [q]atsiti livdok mi ze 'I wanted to check who it was'

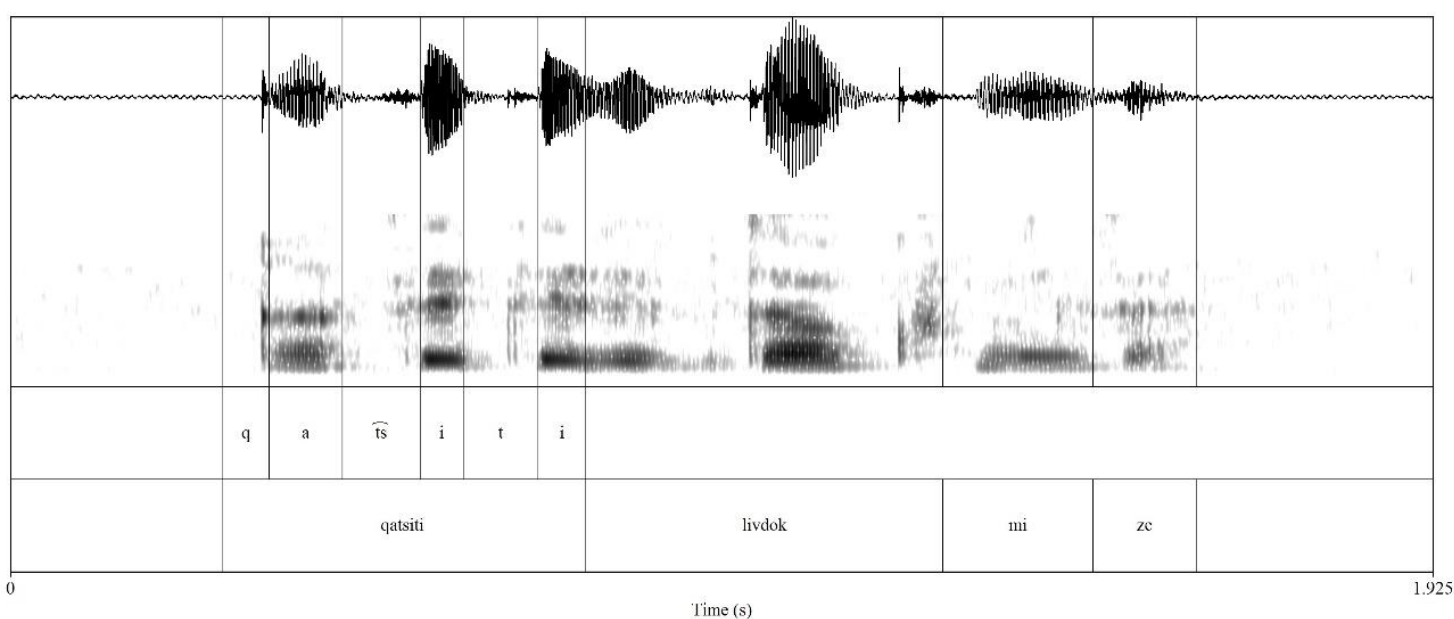




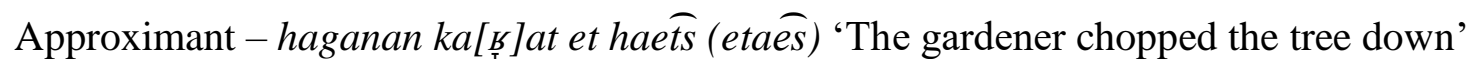

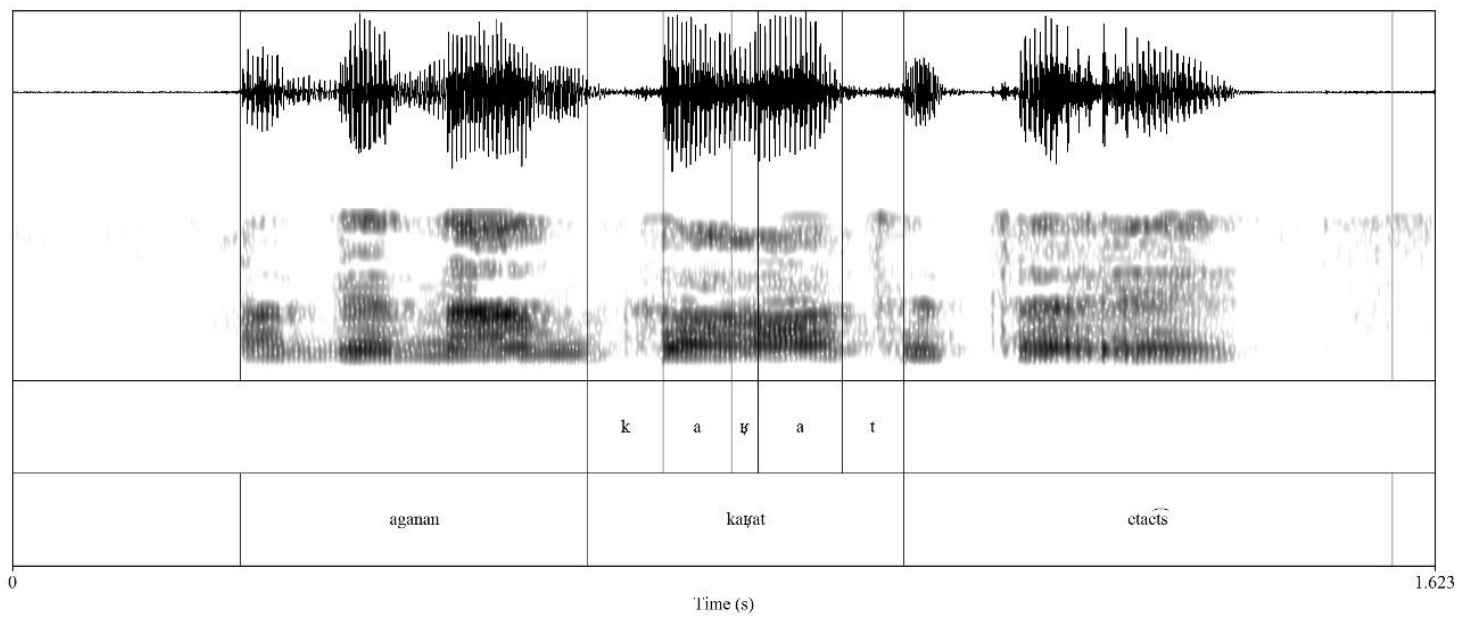

Dirty vowel - dani ka[a] at Pets 'Danny chopped a tree down'

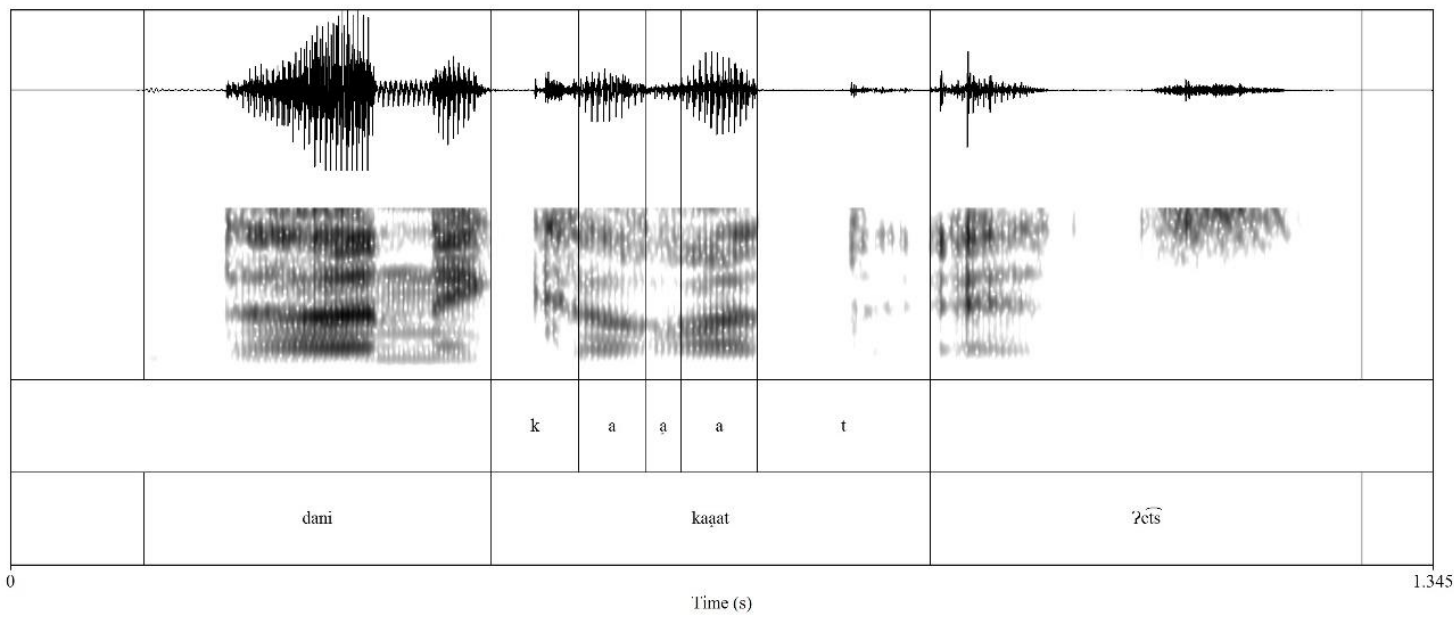

Tap $-[\breve{R}]$ akevet lajla lepașiz 'A night train to Paris'

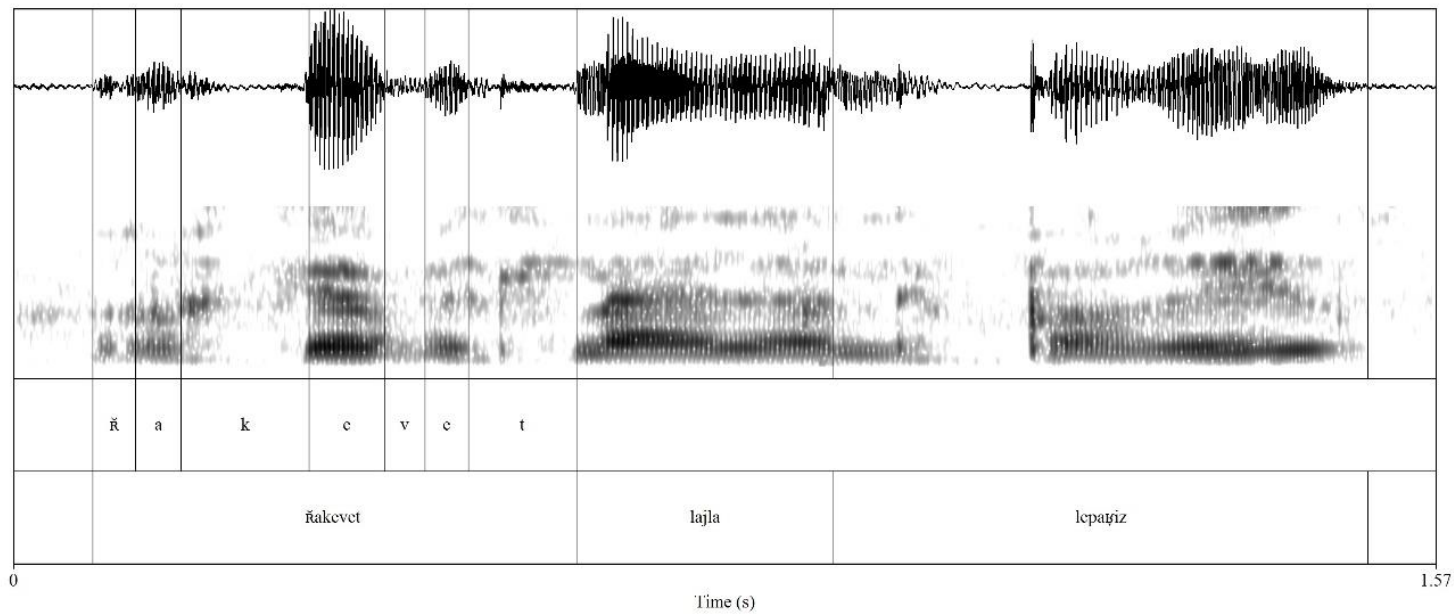


Trill - aganan ka[R]at et aets (etaets) betaut 'The gardener accidentally chopped the tree down'

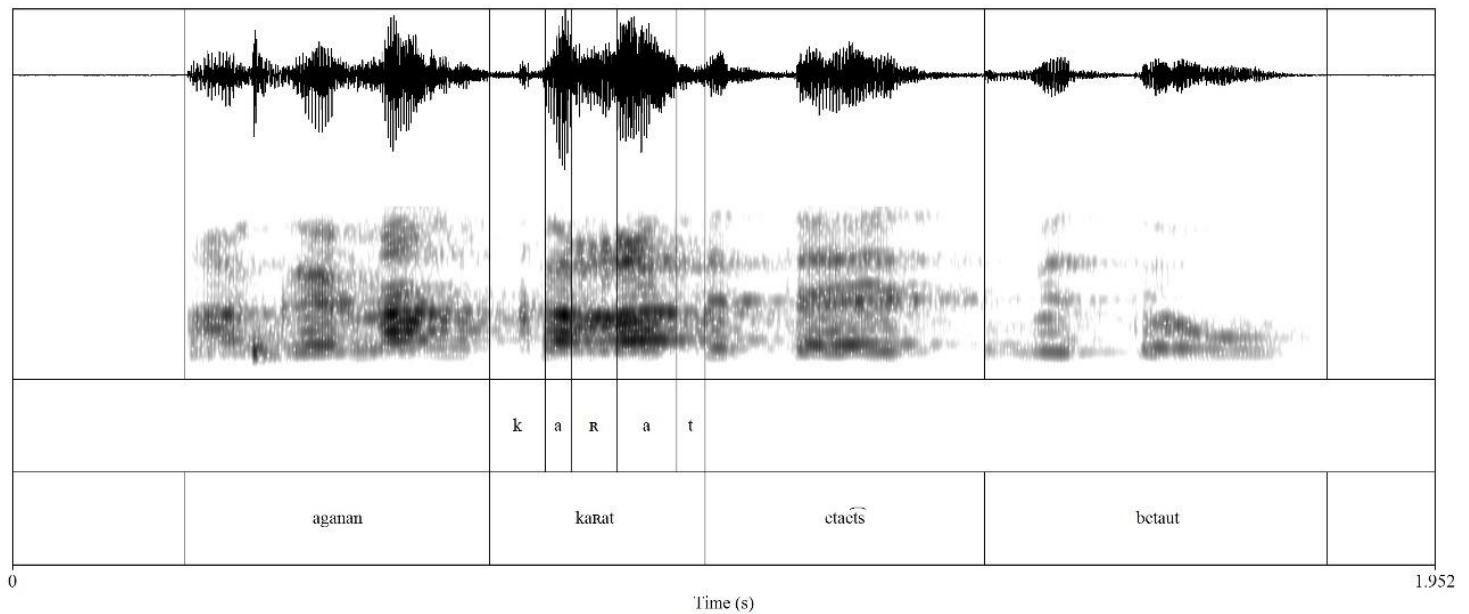

Fricative - $\left[\begin{array}{l}\mathrm{B} \\ \mathrm{b}\end{array}\right]$ afamti leatsmi liknot Poxel 'I made a note to myself to buy food'

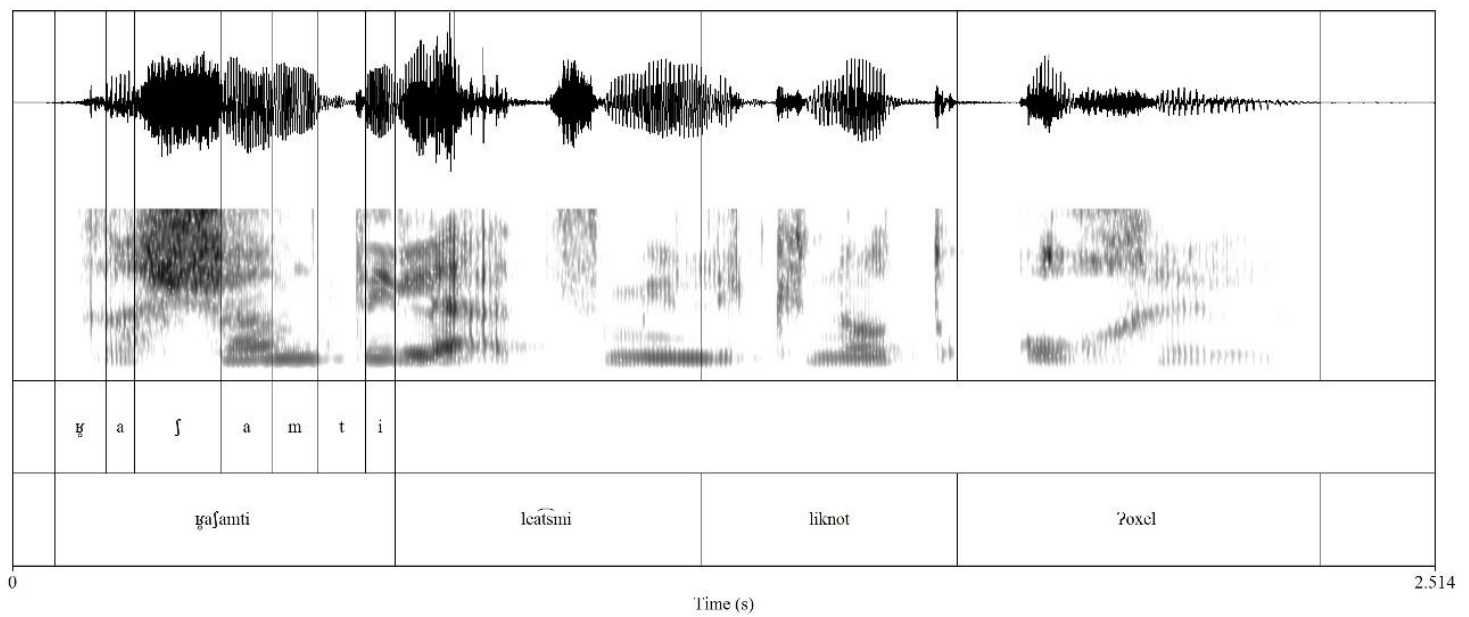




\section{Reference List}

Avram, Andrei. 1993. An experimental study on liquid consonants in Romanian. Phonetics and Dialectology XII, 8-20. [in Romanian]

Baker, Gary K. \& Caroline R. Wiltshire. 2003. An OT treatment of palatal fortition in Argentinian Spanish. In Pérez-Leroux, Teresa \& Roberge (eds.), Romance Linguistics: Theory and Acquisition. Selected papers from the $32^{\text {nd }}$ Linguistic Symposium on Romance Languages (LSRL), Toronto, April 2002, 33-48. Amsterdam: John Benjamins.

Baltazani, Mary and Katerina Nicolaidis. 2011a. Production of the Greek rhotic in initial and intervocalic position. An acoustic and electropalatographic study. Paper presented at the $10^{\text {th }}$ International Conference on Greek Linguistics, Komotini, Greece, September 01-04, 2011.

Baltazani, Mary and Katerina Nicolaidis. 2011b. The many faces of /r/. Paper presented at the R-atics 3 Workshop, Bozen-Bolzano, Italy, December 2-3, 2011.

Ben-David, Avivit. 2001. Language acquisition and phonological theory: Universal and variable processes across children and across languages. Ph.D. dissertation, Tel-Aviv University at Tel-Aviv. [in Hebrew]

Ben-David, Avivit, Ruth Ezrati \& Limor Adi-Bensaid. (submitted). The acquisition of dorsal rhotics.

Blanc, Haim. 1964. Israeli Hebrew texts. In Polotsky \& Rosén (eds.), Studies in Egyptology and linguistics in honour of H. J. Polotsky, 132-152. Jerusalem: Israel Exploration Society.

Boersma, Paul \& David Weenink. 2014. Praat: Doing phonetics by computer. http://www.praat.org/ (accessed 1 June 2014).

Bolognesi, Roberto. 1998. The phonology of Campidanian Sardinian. A unitary account of a self-organising structure. Ph.D. dissertation, University of Amsterdam at Amsterdam. 
Bolozky, Shmuel. 1978. Some aspects of Modern Hebrew Phonology. In Berman (ed.), Modern Hebrew Structure Chapter II, 11-67. Tel Aviv: Universities Publishing Projects.

Bolozky, Shmuel. 1997. Israeli Hebrew Phonology. In Kaye \& Daniels (eds.), Phonologies of Asia and Africa Vol. 1, Chapter 17, 287-311. Winona Lake: Eisenbrauns.

Bolozky, Shmuel. 2009. The weakening of /r/ in colloquial Hebrew. Balshanut Ivrit (Hebrew Linguistics) 62-62, 49-55. [in Hebrew]

Bolozky, Shmuel \& Rina Kreitman. 2007. Uvulars in Israeli Hebrew - their phonetic and phonological status. The National Association of Professors of Hebrew's International Conference on Hebrew Language, Literature and Culture. Sydney, Australia July 2-4.

Catford, John Cunnison. 1977. Fundamental problems in phonetics. Bloomington: Indiana University Press.

Cho, Taehong \& Patricia Keating. 2009. Effects of initial position versus prominence in English. Journal of Phonetics 37, 466-485.

Cho, Taehong, Yoonjeong Lee \& Sahyang Kim. 2014. Prosodic strengthening on the /s/-stop cluster and the phonetic implementation of an allophonic rule in English. Journal of Phonetics 46, 128-146.

Cohen, Evan-Gary. 2013. Prosodic factors in the adaptation of Hebrew rhotics in loanwords from English. In Spreafico \& Vietti (eds.), Rhotics. New data and perspectives, 191-206. Bozen-Bolzano: Bozen-Bolzano University Press.

Cohen, Evan-Gary. 2015. Phoneme complexity and frequency in the acquisition of Hebrew rhotics. Journal of Child Language Acquisition and Development 3, 1-11.

Cohen, Evan-Gary \& Avivit Ben-David. (2016). The role of allophony and frequency in the acquisition of the Hebrew rhotic. Clinical Linguistics and Phonetics 30:101-118.

Gottstein, Moshe. 1948. On the accent of the Hebrew 'resh' (/r/). Leshonenu 16, 209-211. [in Hebrew] 
Harris, James W. \& Ellen M. Kaisse. 1999. Palatal vowels, glides and obstruents in Argentinian Spanish. Phonology 16, 117-190.

Hoole, Philip, Marianne Pouplier, Štefan Beňuš \& Lasse Bombien. 2013. Articulatory coordination in obstruent-sonorant clusters and syllabic consonants: data and modelling. In Spreafico \& Vietti (eds.), Rhotics. New data and perspectives, 81-98. Bozen-Bolzano: Bozen-Bolzano University Press.

Itô, Junko \& Armin Mester. 2001. Structure preservation and stratal opacity in German. In Lombardi (ed.), Segmental Phonology in Optimality Theory, 261-295. Cambridge: Cambridge University Press.

Johnson, Keith. 2012. Acoustic and auditory phonetics $3^{\text {rd }}$ edition. Oxford: Wiley-Blackwell. Lindau, Mona. 1985. The story of /r/. In Fromkin (ed.), Phonetic linguistics: Essays in honor of Peter Ladefoged, 157-168. Orlando: Academic Press.

Ladefoged, Peter \& Ian Maddieson. 1996. The sounds of the world's languages. Oxford: Blackwell Publishers.

Laufer, Asher. 1986. Studies in phonetics. Jerusalem: The Israeli Academy of Sciences and Humanities. [in Hebrew]

Laufer, Asher. 1992. Phonetics and Phonology, Units 4-5 of the course "Introduction to Linguistics". Tel-Aviv: The Open University of Israel. [in Hebrew]

Mizrachi, Avi. (in progress). Voicing assimilation and acoustic correlates of voicing in Hebrew. M.A. thesis, Tel-Aviv University at Tel-Aviv.

Most, Tova, Ofer Amir, and Yishai Tobin. 2000. The Hebrew vowel system: raw and normalized acoustic data. Language and Speech 43, 295-308.

Pierrehumbert, Janet, Tessa Bent, Benjamin Muson, Ann Bradlow and J. Michael Bailey. 2004. The influence of sexual orientation on vowel production. Journal of the Acoustical Society of America 116(4), 1905-1908. 
Raffelsiefen, Renate. 2014. The grammar of coercible segments: implications for phonological abstractness. The Israeli Phonology Circle. Tel Aviv, Israel July 7.

Savu, Carmen F. 2012. On the phonetic structure of the rhotic tap and its phonological implications. M.A. thesis, University of Bucharest at Bucharest (available at http://ling.auf.net/lingbuzz/001548).

Schwarzwald, Ora R. 1981. Grammar and reality in the Hebrew verb. Ramat Gan: Bar Ilan University Press.

Segal, Moshe Z. 1928. Foundations of Hebrew phonetics: A study in the phonetics of Hebrew and its history. Jerusalem: HaSefer. [in Hebrew]

Siegelman, Yitzchak. 1950. Foundations of Hebrew sounds. Tel-Aviv: Yavneh Publishing House. [in Hebrew]

Smith, Jennifer L. 2002. Phonological augmentation in prominent positions. Ph.D. dissertation, University of Massachusetts at Amherst.

Storm, Sandra. 1974. Modern Hebrew Phonology: A generative approach. Ph.D. dissertation, The University of Wisconsin.

Torczyner, Naftali H. 1936. The joyful accent: Lectures on Radio Jerusalem for the correction of the Hebrew accent. Jerusalem: Va'ad HaLashon HaIvrit. [in Hebrew]

Vago, R.M. and M. Gósy. 2007. Schwa vocalization in the realization of /r/. Proceedings of the $16^{\text {th }}$ International Congress of Phonetic Sciences, 505-509. Available at <http://www.icphs2007.de/conference/Papers/1080/1080.pdf>. 